\title{
A Study of the Correlation between Non-English-Majored Graduates' Scores of College English Test 6 and Tolerance of Ambiguity
}

\author{
Yougen Lou', Pei Xu², Honglian Liu ${ }^{3}$, Xiaoxu Wei ${ }^{4}$ \\ ${ }^{1}$ School of Foreign Studies, Yangtze University, Jingzhou, China \\ ${ }^{2}$ Paotong Elementary School, Wuhan, China \\ ${ }^{3}$ Jingzhou Experimental Middle School, Jingzhou, China \\ ${ }^{4}$ College of Foreign Language, Hunan University, Changsha, China \\ Email: louyougen@163.com
}

Received 5 October 2015; accepted 21 November 2015; published 24 November 2015

Copyright $\subset 2015$ by authors and Scientific Research Publishing Inc.

This work is licensed under the Creative Commons Attribution International License (CC BY). http://creativecommons.org/licenses/by/4.0/

(c) $\underset{\mathrm{EY}}{\mathrm{EY}}$ Open Access

\section{Abstract}

This paper is a study of effects of non-English-majored graduates' tolerance of ambiguity (TA) on their scores of College English Test grade 6. The subjects for this study are 115 non-Englishmajored graduates from Yangtze University. The results in this study showed that the non-Englishmajored graduates' TA was varied and their TA distributed normally; their TA was significantly correlated with their scores in listening and their total scores; there was a weak positive correlation between their TA and their scores in reading; but their scores in writing were not significantly correlated with their TA. The author hopes that the results and analyses in the paper will be a bit helpful to foreign language teaching and learning in China.

\section{Keywords}

Non-English-Majored Graduates, Scores, Tolerance of Ambiguity

\section{Introduction}

Foreign language learning, a complex process, is affected by various factors such as learning environment, emotion, learner's personality. Tolerance of ambiguity is an important learner's personality factor. Frenkel-Brunswick (1948) originally developed the concept of tolerance of ambiguity (TA) from intolerance of ambiguity. 
Frenkel-Brunswick (1949) defined TA as an "emotional and perceptual personality variable”. Frenkel-Brunswick $(1949,1951)$ argued that TA generalises to the various aspects of emotional and cognitive functioning of the individual, characterizing cognitive style, belief and attitude systems, interpersonal and social functioning and problem solving behavior. She also related TA to other personality variables, predicting a positive relationship with the authoritarian family of personality traits. So a person with a low TA is likely to view uncertainty as psychological discomfort or threat. Oxford (1999) defined TA as "Tolerance of ambiguity is the acceptance of confusing situations". So a person with a high TA is likely to accept uncertainty as ease.

Ehrman (1999) divided TA into three levels of functions. The first level is to permit information to enter one's conceptual schema in the first place, which is called as intake. The second level is that TA proper, intake has been successfully accomplished, and the learner can cope with contradictions and incomplete information or incomplete constructs. The third level is that the learner makes discriminations, sets priorities among competing concepts, develops hierarchies of information in terms of level of abstraction, and restructures cognitive schema (Arnold, 1999).

The author makes a study of the correlation between learners' scores on the COLLEGE ENGLISH TEST (grade six) (CET 6) and TA have a better understanding of how TA functions in foreign language teaching and learning.

The purpose of this study was to investigate the correlation between non-English-majored graduates' scores of CET 6 and TA. More specifically, this study attempted to answer the following questions:

1) What is the general effect of TA on the test?

2) Is there the relationship between non-English-majored graduates' scores of CET 6 and TA?

\section{The Relationship between TA and Foreign Language Learning}

Many scholars believe that there is a close relationship between TA and foreign or second language learning.

Oxford (1999) claimed, "Second language learning has a great deal of ambiguity about meanings, referents and pronunciation, and this can often raise language anxiety. Therefore, a degree of ambiguity tolerance is essential for language learners".

Ehrman (1999) concluded, "Tolerance of ambiguity is crucial to success in language learning aimed at real communication use. Students who lack ambiguity tolerance tend to have a great deal of trouble in language learning, both formal and informal” (Arnold, 1999: p. 75).

Chinese scholar Wang Chuming (1990: 129) cautioned that the relationship between TA and foreign languge learning mostly remained at the level of inference and that there is not sufficient experimental evidence. There are three practical investigations on the issue. Naiman et al. (1987: 100) found that TA was one of only two significant factors in predicting success of high school learners of French in French Toronto. They also found that learners with a high TA get higher scores in listening tests. Chapelle \& Robers (1986) measured TA among learners of English as a second language in Illiois. They found that learners with a high TA were slightly more successful in certain language tasks.

\section{Research Methods}

\subsection{Subjects}

The subjects of the study are 115 first-year non-English-majored graduates in 4 classes from Yangtze University. Their majors are chemistry, agriculture, plant protection, animal medicine, animal science, finance and biological technology participated in this study. Among the 115 subjects, 60 were females and 55 males, average age 22 with Chinese.

\subsection{The Instruments}

\subsubsection{The Test Papers of CET6 of June, 2014}

The students took part in the test CET6 (710) in June 2014. These scores are the evidence to show their achievement in English learning.

\subsubsection{A Questionnaire}

The author designed the questionnaire on TA on the basis of some scholars' discussion of TA. Before the ques- 
tionnaires were distributed to students, 10 students were randomly chosen by the author to test the reliability of the questionnaire on TA as the pretest. The reliability of the questionnaire on TA is 0.76 . The questionnaire consists of 20 questions in Chinese, and the choices for each question are of five levels:

A. Absolutely agree (1) B. Agree (2) C. Uncertain (3) D. Disagree (4) E. Absolutely disagree (5). The full score for each paper is 100.115 copies of were distributed to 115 non-English-majored graduates and all 115 questionnaire were valid.

\subsection{Data Collection and Data Procedures}

Data collection was conducted through the test papers of CET6 (710) and the questionnaires. The results of scores of the test CET6 and the scores of questionnaires were inputted to a computer and SPSS + 13.0 statistical analysis was adopted to make analyses. The methods of Person correlation and 2-tail test were used as statistical analysis in this study.

\section{Results}

\subsection{Descriptive Statistics}

As shown in Table 1, descriptions of scores of the test CET6 were from three aspects: writing, listening and reading. Non-English-majored graduates' scores of the test CET6, Total $($ Mean $=426.76$, S.D. $=18.78)$ showed their scores of the test CET6 were common on the whole. The scores of writing, listening and reading are obvious differences between minimum and maximum.

\subsection{A Comparison between the Scores of TA and the Writing Part (WP), the Listening Part (LP), the Reading Part (RP) in the Test}

As shown in Table 2, non-English-majored graduates' TA was different kinds. Their scores of TA were from below 34 to above 60, and their average scores of WP in the test, their average scores of LP in the test, their average scores of RP in the test were, respectively, from 155.10 to 177.22 , from 120.10 to 191.10 , and from 136.45 to 205.35. The scores of TA (below 34) and average scores of WP in the test (155.10) suggested that

Table 1. Descriptions of scores of the test CET6.

\begin{tabular}{|c|c|c|c|c|c|}
\hline & $\mathrm{N}$ & Minimum & Maximum & Mean & S.D. \\
\hline Writing & 115 & 92 & 189 & 169.45 & 15.80 \\
\hline Listening & 115 & 103 & 197 & 161.35 & 13.53 \\
\hline Reading & 115 & 83 & 202 & 176.56 & 12.06 \\
\hline Total & 115 & 281 & 546 & 426.76 & 18.78 \\
\hline Valid N & 115 & & & & \\
\hline
\end{tabular}

Table 2. A comparison between the scores of TA and WP, LP, RP in the test.

\begin{tabular}{ccccc}
\hline The scores of TA & N & Average scores of WP & Average scores of LP & Average scores of RP \\
\hline Below 34 & 9 & 155.10 & 120.10 & 136.45 \\
$35-39$ & 11 & 162.21 & 135.23 & 151.34 \\
$40-44$ & 18 & 167.23 & 148.25 & 164.56 \\
$45-49$ & 20 & 168.24 & 156.34 & 173.34 \\
$50-54$ & 21 & 171.34 & 167.45 & 180.23 \\
$55-59$ & 25 & 173.25 & 178.35 & 191.34 \\
60 and above & 11 & 177.22 & 191.10 & 205.35 \\
\hline
\end{tabular}


students with a low TA got lower average scores of WP in the test, compared to students with a higher TA (60 and above) getting higher average scores of the listening part of LP in the test (177.22). And the scores of TA (below 34) and average scores of LP in the test (120.10) suggested that students with a low TA got lower average scores of LP in the test, compared to students with a higher TA (60 and above) getting higher average scores of the listening part of LP in the test (191.10). It was similar that the scores of TA (below 34) and average scores of RP in the test (136.45) suggested that students with a low TA got lower average scores of LP in the test, compared to students with a higher TA (60 and above) getting higher average scores of the listening part of LP in the test (205.35).

\subsection{Correlation}

As shown in Table 3, there were correlations between TA and listening $(r=0.453)$, reading $(r=0.243)$ and total $(r=0.451)$, but there was no correlation between TA and writing $(r=0.109)$. The results in Table 3 showed that non-English-majored graduates' TA affected their scores of listening, reading and total in the test CET6 more than writing in the test CET6.

\section{Discussion}

From the statistics above, we know that the non-English-majored graduates' TA is varied and it correlates with their scores in listening, reading and their total scores. The correlations between the non-English-majored graduates' TA and the scores of all three items (listening, reading and their total scores) are lower the level 0.01 . According to methods described by Liu Runqing (1999: 176-177), with the prerequisite that the samples are no less than 100, the two correlate with each other slightly when the correlation is between 0.2 and 0.35 , and the correlation is significant when it is between 0.35 and 0.65 , and a rough prediction to a group can be conducted when it is 0.4 and above. The correlation between the non-English-majored graduates' TA and the scores of reading $(r=0.243)$ is below 0.35 , so there is slight correlation between them. And the correlation between the non-English-majored graduates' TA and the scores of listening $(r=0.453)$ is above 0.35 , so there is stronger correlation between them. Table 2 shows a positive correlation between the non-English-majored graduates' TA and their scores. That's to say, non-English-majored graduates with the higher TA get their better scores in the test, which agrees with the findings from Chapelle \& Robers (1986) and Naiman et al. (1987). But the correlation between TA and scores in writing is not significant $(P=0.154>0.05)$.

The results in this study agree with the claims of Naiman et al. (1987) that those who tolerate ambiguity are likely to have better scores in listening tests. The results in this study show that non-English-majored graduates' TA is closely linked to their scores in the test CET6. Therefore, we may predict that students with a high TA are beneficial to their foreign language learning and students with a high TA will be slightly more successful in foreign language learning. Just like Chapelle \& Robers (1986) found that learners with a high TA were slightly more successful in certain language tasks. In foreign language learning, students are encouraged to deal with a lot of unclear content, contradictory or incomplete information, and so on. And they feel anxious and frustrated in their learning. Non-English-majored graduates, in listening tests, are easily to become tense and anxious due to restrictions with time and their performance on the test will be influenced by this tense and anxiety. But the scores in writing don't correlate with TA, which show that there is a slight association between language output, mastery of language knowledge and TA. Reading is a kind of language input which concerns the students' TA,

Table 3. Correlation.

\begin{tabular}{cccccc}
\hline & TA & Writing & Listening & Reading & Total \\
\hline TA & & & & \\
Pearson Correlation (r) & 1.000 & 0.109 & $0.453^{* *}$ & $0.243^{* *}$ & $0.451^{* *}$ \\
P & & 0.154 & 0.000 & 0.000 & 0.000 \\
N & 115 & 115 & 115 & 115 & 115 \\
\hline
\end{tabular}

\footnotetext{
${ }^{* *}$ Correlation is significant at the level $<0.01(P)$.
} 
their language proficiency and their familiarity with the content. Therefore, in reading, there is a slight correlation between the students' TA and their scores.

\section{Limitation and Suggestions}

Though the present study has provided a comparatively detailed description of TA applied among some firstyear non-English-majored graduate students, there are still some limitations of the study. Having the limitations in mind, suggestions for further research, therefore, can be put forward at the same time in order to achieve a lot thorough understanding of TA and foreign language learning.

Firstly, being time limitation (only half year) and other practical restrictions such as the subjects in the study consisted of only 115 non-English-majored graduate students in one university need to be broadened in further research.

Secondly, the instruments used to investigate non-English-majored graduate English teaching and learning with TA involve tests and structured questionnaire. The study would be much better, if it were combined with other instruments such as observation, verbal report. More instruments should be used in investigation in further research.

Finally, TA applied in non-English-majored graduate English teaching can influence non-English-majored graduate students' English learning, but TA also works for other subjects such as undergraduate students, we need further research.

Despite of the restraints of the study, it is hoped that it can offer some guidelines for further research on TA applied in English teaching and learning.

\section{Conclusion}

115 non-English-majored graduates participated in this study. The results in this study showed that the nonEnglish-majored graduates' TA was varied and their TA distributed normally; their TA was significantly correlated with their scores in listening and their total scores; there was a weak positive correlation between their TA and their scores in reading; but their scores in writing were not significantly correlated with their TA. NonEnglish-majored graduates could benefit from a high TA in foreign language learning. As non-English-majored graduates they should manage to heighten their TA, and the teachers also should help their students improve their TA in many ways, such as helping non-English-majored graduates have a correct understanding of the main goal of foreign language learning, instructing them in learning methods, and so on.

\section{References}

Chapelle, C., \& Roberts, C. (1986). Ambiguity Tolerance and Field Independence as Predictors of Proficiency in English as a Second Language. Language Learning, 36, 27-45. http://dx.doi.org/10.1111/j.1467-1770.1986.tb00367.x

Ehrman, M. (1999). Ego Boundaries and Tolerance of Ambiguity in Second Language Learning. In J. Arnold (Ed.), Affect in Language Learning (pp. 68-86). Cambridge University press.

Frenkel-Brunswick, E. (1948). Intolerance of Ambiguity as an Emotional and Perceptual Personality Variable. Journal of Personality, 18, 108-123. http://dx.doi.org/10.1111/j.1467-6494.1949.tb01236.x

Frenkel-Brunswick, E. (1949). Tolerance toward Ambiguity as a Personality Variable. American Psychologist, 3, 268.

Frenkel-Brunswick, E. (1951). Personality Theory and Perception. In R. Blake, \& E. Ramsey (Eds.), Perception: An Approach to Personality. New York: Ronald. http://dx.doi.org/10.1037/11505-013

Liu, R. Q. (1999). Research Methods in Foreign Language Teaching (pp. 472-473). Beijing: Foreign Language Teaching and Research Press.

Naiman, N. M., Frohlich, M., \& Stern, H. H. (1987). The Good Language Learner. Toronto: Ontario Institute for Studies in Education.

Oxford, R. L. (1999). Anxiety and the Language Learner: New Insights. In J. Arnold (Ed.), Affect in Language Learning (pp. 68-86). Cambridge University press.

Wang, C. M. (1990). Applied Psycholinguistics (pp. 28-130). Beijing: Beijing Normal University Press. 